\title{
Contraceptive use among sexually active female adolescent in Ethiopia: Trends and determinants insight from national demographic and health survey
}

\author{
Alemi Kebede Olika ( $\square$ alemikebede@gmail.com ) \\ Jimma University \\ Sena Belina Kitila \\ Jimma University \\ Yonas Biratu Terfa \\ Jimma University \\ Ayantu Kebede Olika \\ Jimma University
}

Research

Keywords: Ethiopia, adolescent, contraceptives, Demographic and health survey, Determinants

Posted Date: November 9th, 2020

DOI: https://doi.org/10.21203/rs.3.rs-34459/v3

License: (c) (i) This work is licensed under a Creative Commons Attribution 4.0 International License.

Read Full License 


\section{Abstract}

Background: Sexual and reproductive health and right of young people is a global priority as the reproductive choices made by them have a massive impact on their health and wellbeing, education and economy. Teenage pregnancy is a burning public health issue and a demographic challenge in Ethiopia. The use of contraceptive method is a most effective way for sexually active adolescent to prevent pregnancy and its related complication. However, little is known about the trends in contraceptive use and its determinant among girls aged 15 to 19 in Ethiopia. Therefore, this study was designed to examine the trends and correlates of contraceptive use among sexually active adolescents in Ethiopia by using Ethiopian demographic and health survey data.

Methods: Four Ethiopian demographic and health survey data were used to examine trends of contraceptive methods use among sexually active adolescent girls. To identify factors associated with contraceptive use, the 2016 Ethiopian demographic and health survey data were used. The data was accessed from the demographic and health survey program data base and data for sexually active adolescent girls were extracted. Data analysis was done using SPSS version 21. Data were weighted for analysis. Descriptive analysis was used to describe independent variables of the study. Multivariable logistic regression model was used to identify factors associated with contraceptive use.

Results: Contraceptive method use was increased significantly from $6.9 \%$ in 2000 to $39.6 \%$ in 2016 among sexually active adolescent girls in Ethiopia. The odds of contraceptive use were lower among female adolescent who had no formal education ( $\mathrm{AOR}=0.044 ; 95 \% \mathrm{Cl}=0.008-0.231$ ) and attended primary education $(\mathrm{AOR}=0.101 ; 95 \% \mathrm{Cl}=0.024-0.414)$. But the odds of contraceptive methods use were higher among adolescents in rich wealth status (AOR $=3.662 ; 95 \% \mathrm{Cl}=1.353-9.913)$ and those who were told about family planning during their health facility visits (AOR=3.115;95\% $\mathrm{Cl}=1.385-7.007)$

Conclusion: Contraceptive method use was increased significantly among sexually active adolescent girls in Ethiopia in the year 2000 to 2016. Wealth status, educational status and information about family planning during their health facility visits were factors associated with contraceptive use. Improving economic and educational status of young women may help in improving contraceptive use in Ethiopia.

\section{Introduction}

Adolescence is a critical phase in life and a time of social and biological transition between childhood and adulthood that entails numerous milestones and opportunities, roles, and responsibilities $(1-3)$. Adolescents: Individuals in the age range of 15-19 years are central to sustainable development since they are a driving force for development. This age group contributes up to 16 percent of the world's population and is one of the fastest growing cohort (4-6).

Although adolescent populations are huge in number and their contribution is important in achieving several developmental goals, an explicit attention has not given to adolescent during millennium development goals (5). However, recently, global developmental goals and strategies recognized 
adolescents as a previously neglected population group and emphasized the importance of their health and rights $(7,8)$. The 2016 lancet commission report on adolescent also indicated the triple dividend of investing in adolescent (6). Investments done for adolescent supported them to become healthy adults who are equipped to contribute positive to societies (9).

Sexual and reproductive health and right of young people is a global priority as the reproductive choices made by them have a massive impact on their health and wellbeing, education and economy $(10,11)$. In addition, children born to adolescent girls are more likely to have low birth weight (12). Among girls in developing regions, about half of all pregnancies are unintended. More than half of these pregnancies result in abortion, whereas, $14 \%$ were unsafe abortions (10), an annual rate of about 16 unsafe abortions per 1,000 occur among girls under the age of 20 years in developing (13). These early and unintended pregnancies have major health consequences for both mothers and their babies; pregnancy and childbirth complications are the leading cause of death among adolescent girls globally, with a higher proportion in low- and middle-income countries $(14,15)$.

Access to sexual and reproductive health information and services including high-quality contraceptive methods services are essential in averting the burden of early pregnancies, unintended pregnancies and births and abortion $(4,6,11,16)$. The use of the contraceptive method is a most effective way for sexually active adolescent to prevent pregnancies and its related complication (10). For instance, the use of modern contraceptives prevents an estimated 308 million unplanned pregnancies in 2017 (11), and if all adolescent with an unmet need for modern contraception were to receive the services, unintended pregnancies would drop by $59 \%$ from current levels (10). In addition, evidence from developing countries indicated the relationship between improving access to contraceptives and unsafe abortion, and expanding contraceptive method mix can serve as an effective strategy to prevent unsafe abortion (17). Hence, all adolescents who want to prevent pregnancy should able to obtain and use contraception (18).

Available evidences showed that sexually active unmarried adolescents are not seeking to become pregnant and married wish not to become pregnant at a young age or wish to delay a second pregnancy $(11,14,19,20)$. However, there is a high unmet need for modern contraceptive use among adolescent. For instance, to avoid an unintended pregnancy, 38 million adolescents in developing countries need contraceptives, however, only $40 \%$ are using an effective contraceptive method (10)(21). Despite having clear needs, adolescents and young adults often fail to access sexual and reproductive health care and unplanned pregnancies happen despite the best of contraceptive intentions $(5,6,22)$. Although efforts are made to eliminate inequalities in the utilization of sexual and reproductive health services across the globe, there are disparities in contraceptive use between different age groups and young people have inadequate access to sexual and reproductive health information and services.

In Ethiopia teenage pregnancy is a burning public health issue, and a demographic challenge. The proportion varies geographically with $15 \%$ in rural and $5 \%$ in urban (22). Preventing teenage pregnancies and fertility are among the priority issues of the Ethiopian Federal Ministry of Health (23). The 
government of Ethiopia is implementing policies and strategies to support young people in increasing their access to sexual and reproductive health services (24-26).

Despite studies are available for contraceptive use in Ethiopia, there is scarcity of studies using national level data to assess the trends in contraceptive use, and its correlates among girls aged 15 to 19 years. To effectively respond to the reproductive health needs of this growing population, it is imperative to understand their contraception practices. Therefore, the purpose of this study was to examine the trends, and correlates of contraceptive use among sexually active adolescents in Ethiopia by using the Ethiopian demographic and health survey data. This will be useful to planners for health programming of the country and all other stakeholders who are working to improve the health and well-being of adolescents in Ethiopia. Furthermore, it will assist in designing strategies and programs to better address coverage, quality, and equity issues at the country level as this paper sought to examine the trends of contraceptive using four Ethiopian DHS.

\section{Data And Method}

Data for this study are from the four consecutive years' $(2000,2005,2011$, and 2016) Ethiopian Demographic and Health Surveys [EDHS]. The information about contraceptive use was collected from all non-pregnant, fecund reproductive age women using pretested questionnaire. The detail about the methodology could be accessed from (www.measuredhs.com). In this study, all the four EDHS data were used to describe the trends of contraceptive use among sexually active female adolescent. The 2016 EDHS data were employed to analyze the determinants of contraceptive use.

The 2016 survey comprising 15,683 women aged 15- 49 and 12,688 men aged 15- 59. Among total interviewed women, 6,401 of them were youth; $15-19$ girls account 3,498 (22.3\%). Data for sexually active adolescent girls were extracted from the data set. Of the total adolescent girls participated in the study, 518 were sexually active in the last four weeks before data collection. The data set was requested from the Measure DHS program on April 1, 2019. An approval was then granted for accessing the data.

The dependent variable for this study was contraceptive use. Some selected independent variables include: Age, educational status, religion, ethnicity, marital status, working currently, wealth status, visiting of health facility, hearing about family planning information from radio, Television (TV), newspaper, place of residence and region of residence, told about family planning at the health facility.

For this study, some of the study variables were re-coded to suit the purpose of the study while some were used as they are in the original data set. For instance, religious affiliation was re-coded into orthodox Christian, other Christian and Muslim. Wealth status was also re-coded into poor, average, and rich by combining "poorer" and "poor" for poor and "rich" and "richer" for rich. The highest education level was recoded into no education, primary, and second and above by combining secondary and higher.

The data were analyzed using SPSS version 21. Before any statistical analysis, standard EDHS sample weights were applied to account for the unequal probability of selection in the sample and non-response. 
The recommended procedure on how to weight DHS data in SPSS was followed. The weighting variables used was women's individual sample weight, since the study unit of analysis is women. Descriptive analysis was used to describe background characteristics of the study participants. Multicollinearity was checked before running logistic regression using variance inflation factor. The maximum value of the variance inflation factor was 1.119 , indicating that the absence of multicollinearity. Binary and multiple logistic regressions were employed to identify candidate variables and examine the determinants of contraceptive use respectively. Adjusted odds ratios with $95 \%$ confidence interval were presented for significant variables in the final model to estimate the likelihood of contraceptive use among various categories of adolescents. All figures and tables in the report depict weighted numbers and percentages.

\section{Operational definition of terms}

Adolescent: Individuals whose age are between 15 to 19

Sexually active: Those respondents who reported that they have had sexual intercourse, irrespective of their marital status in the last four weeks at the time of interview.

Contraceptive use: Respondents who at the time of interview said they or their partner are using any contraceptive method to delay or avoid becoming pregnant. It was dichotomous denoting users, and nonusers of contraceptive methods.

Current use of modern contraception: Current users of modern contraceptives include young women who said that they or their partner are currently using any of the following modern methods of contraception, such as female sterilization, male sterilization, the pill, injectable, intrauterine device, implant, condom, and emergency contraception at the time of the survey.

\section{Results}

\section{Trends in contraceptive use}

The trends of contraceptive use among sexually active female adolescents increased from 6.9 percent in 2000 to 39.6 percent in 2016, increased by more than 6 -fold. Regarding the types of contraceptives used, the proportion of modern contraceptive method use has significantly increased. It has increased by 8.7 percent during the survey period from 2000 to 2005 and nearly doubled between 2005 to 2011 . The proportion of adolescent who has used modern contraception methods continuously increased between the years 2005 and 2016 and, more than 10 percent increment was observed between 2011 and 2016 (Figure 1).

\section{Differentials in contraceptive use by background characteristics}

The proportion of contraceptive use varies significantly with age, place of residence, educational level of a respondent, and household wealth status. 
In all four surveys, modern contraceptive use was more common among adolescents with secondary and above educational status, in urban areas, in the age category of 18-19 and who have rich family. The percent of girls with secondary and above educational level and using a method has no change during 2005 to 2011 and significantly declined by 6.3 percent between 2011 and 2016 (Figure 2).

\section{Modern contraceptive trend by method mix}

The trends in mix of currently used modern methods indicated promising improvement. The share of long acting reversible contraceptive method such as Norplant/implants among sexually active adolescent girls has significantly increased by more than 6 percentage between 2000 to 2016. Intrauterine device (IUD) use did not increase compared to implant; implants increased to $6.3 \%$, whereas, only $1.1 \%$ increment on IUD in 2016. Regarding the observed shifts in the prevalence of short-term methods, the share of injection methods of contraception has significantly increased by more than 25 percent from the year 2000 to 2016 . The uses of condoms as significantly declined between the years 2005 and 2016 from $1.7 \%$ to $0.1 \%$ (Figure 3 ).

\section{Socio demographic characteristics of the adolescent girls by using 2016 EDHS}

The total of 504 sexually active adolescent girls were considered for this study. The mean age of the respondents was $17.73( \pm 1.124)$. The mean ages at first cohabitation and first sexual intercourse were $15.59( \pm 1.734)$ and $15.63( \pm 1.751)$ years respectively. About half, $225(47.3 \%)$ of them cohabited at age 15 years and less than.

Three fifths (60.6\%) of the sexually active adolescent girls have attended primary education and $87.3 \%$ (440) were from rural residents; while 458 (91.0\%) were married, and likewise 125 (24.8\%) were from poorer socioeconomic group. Slightly more than two fifths $(41.9 \%)$ of the girls were Muslim by religion and 199 (39.5\%) were Oromo by Ethnicity. More than three fourth $(79.7 \%)$ of the girls were not working at the time of the survey (Table 1).

Exposure to family planning information, knowledge about fertility and contraceptive method

Among sexually active adolescent girls, only $18.1,13.4$ and 4.2 percent of them reported that they had heard family planning messages on radio, watched on Television and read on newspaper/magazine respectively in the last few months before the survey. More than three fourth $(79.9 \%)$ girls reported that they were not visited by field workers in the last 12 months before the survey. Out of those visited by fieldworker, only $9.9 \%$ of fieldworker talked about family planning. Additionally, only 77 (15.3\%) were told about family planning among girls visited health facility in the last 12months (Table2).

Sexually active adolescent girls in Ethiopia had limited knowledge about a fertile period. Only $15 \%$ correctly knew the ovulatory period. Almost all, 494 (98\%) of the sexually active adolescent girls knew about contraceptive methods (Table2).

Factors associated with contraceptive use among sexually active adolescents 
In binary logistic regression eleven variables had significant relationship with adolescent girls' contraceptive use. These include respondent's and partner's educational and occupational status, currently working status, wealth status, visited by field worker in the last 12 months, told about family planning at a health facility, place of residence, heard family planning messages on radio on the last few months, and watch family planning messages on Television on last few months. However, in the multi variable logistic regression, there is no significant relationship between the adolescent contraceptive use and the type of place of residence, respondent's occupation, heard family planning messages on radio on the last few months, watch family planning messages on Television on the last few months and visited the health facility.

The odds of contraceptive use were nearly $96 \%$ (AOR $=0.044 ; 95 \% \mathrm{Cl}=0.008-0.231)$ and $90 \%(\mathrm{AOR}=0.101$; $95 \% \mathrm{Cl}=0.024-0.414$ ) less likely among sexually active female adolescent who had no education and primary education respectively compared to their counterparts who had attended secondary and above educational level. Adolescent living in a rich wealth status were higher than 3-times more likely to use contraceptive as compared to adolescents in poor wealth status (AOR=3.662; 95\% $\mathrm{Cl}=1.353-9.913$ ). The odds were 3-times among respondents who had visited health facility and told about family planning compared to their counterparts who had not told about FP during their visit (AOR=3.115; $95 \% \mathrm{Cl}=1.385-$ 7.007) (Table 3).

\section{Discussion}

This study examined the trend and correlates of contraceptive use among sexually active female adolescents in Ethiopia using the national demographic and health survey.

According to the finding of the study, the rates of use of contraception by the adolescents are increasing from time to time over the last decade in Ethiopia. Improvements in the contraceptive prevalence trends were more pronounced between 2005 to 2011 survey years. Possible explanations for this increment may be related to implementation of several interventions aimed at increasing demand for and access to sexual and reproductive health services among adolescents and youths by providing youth-friendly health services and innovative health extension worker program that brings health services including family planning to the communities' home $(27,28)$

There is also a national political commitment to family planning in Ethiopia, governments and nongovernmental organizations have increased resource allocations for contraceptive security and deliver (29). Further, although much of contraception services are provided by government, provision of short term contraception methods by the private sectors can also played an important role in increasing young women's access to contraceptive services in Ethiopia (30).

The proportion of sexually active female adolescent contraceptive users relying on the IUD and implants increased substantially from no reported users in 2000 to $1.1 \%$ and $6.3 \%$ in 2016 respectively. However, IUD use did not increase compared to implants. This may be due to the fact that, starting from 2009 
insertion of implant was cascaded to the health post level and training was given to the health extension workers on the provision of the service.

Despite the progress that has been achieved, a considerable number of sexually active adolescent girls use short acting methods, especially injectable which has a high failure rate compared to long acting and reversible contraceptive methods. The low uptake of long acting and reversible contraceptive methods may be due to barriers such as lack of availability, fear and misconceptions and provider bias on the provision of long acting methods for adolescents $(31,32)$.

The share of injection methods rose from $1.6 \%$ to $29.1 \%$, while the patterns observed in condoms and pill declined from $1.1 \%$ to $0.1 \%$ and $3.2 \%$ to $1.8 \%$ respectively. This finding indicated that adolescent girls appear to be shifting away from condoms and pills, and choosing for injectable contraceptives. This finding is comparable with study from Kenya and Rwanda where, injectable contraceptives have been consistently dominant among women aged 15-24 years (33). Possible reason could be due to the age of the participants. The fertility intention for young population is to delay or space births for two or more years which might explain their preference for short acting methods that are easier to start and stop as needed (34). However, the low use of condoms, and the increasing dominance of injectables have challenges for family planning efforts, and may have significant programmatic and public health implications (35).

Although there are visible changes in the trend of contraceptive use and knowledge of contraception was almost universal, still more than three fifths of sexually active female adolescents are not using the contraception according to 2016 EDHS data. This finding was slightly lower than the report from developing countries where $42-68 \%$ of sexually active adolescent females in all the Latin American countries (except Guatemala and Haiti) and in Bangladesh, Indonesia, Kazakhstan and Turkey were currently using contraceptives (34).

However, it is higher than the results from the African countries where contraceptive prevalence was 20$35 \%$, except in Namibia in which it reached at least $40 \%$ (34). Also, this finding was slightly higher than the study from Zimbabwe and Malawi, where $35 \%$ and $33 \%$ of adolescents use contraceptive respectively (36). Further, it was higher compared to figures from Nepal. In Nepal, only $23.1 \%$ of married girls age 15 19 are currently using any method of contraception (37). Non-use of contraception could put adolescent in risks for teenage pregnancy, unintended birth, adverse birth and health outcome $(36,38,39)$. Hence, ensuring access and choice of family planning to improve maternal and neonatal health is crucial.

With an intense knowledge, a huge gap exists between the knowledge and practice of contraceptive methods. This gap may be happened because of contraceptive related side effects. Adolescent may fear side effects associated with using contraception and this could in turn interfere with their practice. Additionally, even though young women's have knowledge about contraception, due to disapproval from their sexual partner, they may not use family planning (40). 
There were significant variations in the use of contraception by background characteristics of adolescent girls in Ethiopia. Adolescents who have secondary and higher educational level, who had information about family planning at health facility, and those in the highest wealthy families use significantly more contraception as compared to their counterpart who have not attended formal education, did not have information about family planning at the health facility, and who belong to the poor families.

This study revealed that respondent's education was an independent predictor for contraceptive use. This was similar to a study conducted in Nigeria and Burkina Faso where contraceptive use among adolescents attended secondary/above level education were higher than those who had completed only primary-level education (41). Similarly, in Ghana, the odds of contraceptive use was higher among educated female adolescents (42). Further, low contraceptive use among illiterate female adolescents was reported in Bangladesh (43). This may be because educated women are more likely to appreciate the dividend that contraceptive use has on their lives. Also educated women may have a plan to pursue the highest career within their education as a result, they want to delay their childbearing time.

The likelihood of contraceptive use increased significantly with the increase in household economic status. This finding was in line with report from three African countries: Nigeria, Burkina Faso and Ethiopia. Across all these countries, there is a significant equity gap in modern contraception use because of wealth index (41). Likewise, another study in Ethiopian showed that women in the richer household were more likely to use contraception (44). This could be because, most of the small resources obtained from the petty jobs done by women, and their spouses in poor households are diverted for taking care of the family and less is shifted to the health of the mothers. Hence, poor household preferred not to use the service as they encountered difficulties to cover direct and indirect costs incurred in seeking the services (45).

Further, adolescents, those had been told about family planning during a health facility visit used contraception more. The existing body of literatures indicated that female adolescent access to family planning information via different sources increases use of modern contraceptive methods. For instance, in Nigeria hearing about family planning on mass media was associated with the use of modern contraceptives (46). Also, being visited by a community health worker resulted in more likely to use modern contraceptive methods (47). Access to information play a significant role in the use of contraception as it has the capacity to raise an individual's awareness, and influence their attitude and could guide to make an informed decision to use the services. However, in the present study only $15 \%$ of those who visit health facilities are told about contraception that indicated many sexually active adolescent girls miss out on this information.

A systematic review that conducted in 2011 and updated in 2016, on youth-friendly family planning services for young people indicated the importance that young people place on receiving comprehensive, client centered family planning counseling (27). However, there are a number of factors that was identified as barriers to the delivery of effective contraceptive counselling and care for adolescents. For instance, in Latin America, many consider adolescent use of contraception to be socially unacceptable 
(48). Since there were significant associations between FP counseling with contraceptive initiation, as well as continuation, health care provider skills in the counselling, and provision of contraception for adolescent are therefore needed be emphasized (49).

According to data from EDHS 2016, more than nine in the ten of adolescents were married and about half were cohabiting at age 15 years and less than; more than three years earlier compared to the recommended age at marriage in Ethiopia. This showed the practice of very early marriage and early sexual activities among adolescent girls.

Early marriage often results from the traditional, and cultural family values that justify control over women's sexuality and fertility (50-52). These types of practices have a direct impact on girls' education and future carrier (53). It has also a negative consequence of the economic development of nations in addition to causing a significant health risk both to a girl, and her baby (54). This was due to an extended time that the girls spend in childbearing years that cause an increase in fertility and population growth. The evidence also indicated that, in marriage union the frequency of sexual activity is higher than in those who are not, hence in the absence of contraception there is greater likelihood of occurrence of a pregnancy (50).

The main strength of this study was the use of a nationally representative data set. The study has also some limitations, the small sample sizes that contributed to a bit wider confidence level for some variables. Possibility of social desirability bias that may result to underreporting of sexual activity. The information was self-reported and it may not indicate the true picture of contraceptive practice by adolescent. The data are from a cross-sectional survey and unable to establish any causal relationship between a response variable (contraceptive use) and the covariates of interest.

\section{Conclusion And Recommendation}

There is an increment in the trend of contraceptive use among sexually active female adolescents in Ethiopia between 2000 to 2016. Although there is change in pattern of implant and IUD use, IUD use did not increase as much and injectable was the most widely used contraceptive method. Respondent education, wealth status and had been told information about family planning at health facility were significant determinants of contraceptive use indicated that personal, social and institutional factors determine the contraceptive practices. Also, a considerable proportion of adolescents are experiencing early marriage that remains a major bottleneck for adolescents.

As adolescent populations continue to grow, governments must develop more targeted strategies for improving socioeconomic and adolescents' education. This will not only increase contraceptive prevalence, but will also reduce teenage pregnancy and childbearing, and in turn contribute to the achievement of the Sustainable Development Goal 3 of good health and well-being. Improving contraception use among sexually active adolescents will also require connecting adolescents with information and services during their routine health service visits and taking advantage on missed 
opportunities for contact with the health facility. Strengthen health workers competency and attitude on counselling, and provision of contraceptive information and services for adolescents is also crucial.

Considering the fact that contraceptive knowledge does not necessarily translate into usable, qualitative studies, are needed to understand why high knowledge levels are not associated with high usage patterns. Strengthening community and school-based programs to address the school environment and/or community attitudes toward early marriage is important. Consequence of early marriage should be emphasis on the integrated Life Skill Education and comprehensive sexuality education. Legal issues around early marriage- enforcing laws on age at marriage should be strengthen.

\section{Abbreviations}

AOR: Adjusted odd Ratio, COR: Crude odd Ratio, DHS: Demographic and Health Surveys, EAs: Enumeration areas, EDHS: Ethiopian Demographic and Health Surveys, HIV/AIDS: Human immunodeficiency virus infection and acquired immune deficiency syndrome, IUCD: Intra-Uterine Contraceptive Device, SPSS: Statistical Package for the Social Sciences, STIs: Sexual transmitted infections, TV: Television

\section{Declarations}

Ethics approval and consent to participate: Manuscript has adhered to the ethical standards. The data set was requested from the Measure DHS program. An approval was then granted to download the data.

Consent for publication: Not applicable

Availability of data and materials: The datasets used and/or analysed during the current study are available from the corresponding author on reasonable request

Competing interests: The authors do not have any conflicting interests to declare.

Funding: There was no funding for this work.

Authors' contributions: AK, SB, AK, YB, Protocol development, AK and SB data analysis and Manuscript preparation and all authors read and approved the final manuscript.

\section{Acknowledgement}

We would like to thank the Demographic and Health Surveys (DHS) Program for availing the data. We also thank Dr. Daniel Taye Feyisa for his support in proofreading this paper.

Availability of data and materials: The raw data available at https://dhsprogram.com/publications/publication-fr328-dhs-final-reports.cfm 


\section{References}

1. Institute of Medicine 2005. Growing Up Global: The Changing Transitions to Adulthood in Developing Countries. Washington DTNAP https://doi. org/10. 17226/1117. The national academies press.

2. Chandra-mouli V, Parameshwar PS, Parry M, Lane C, Hainsworth G, Wong S, et al. A never-before opportunity to strengthen investment and action on adolescent contraception , and what we must do to make full use of it. $2017 ; 1-13$.

3. Patton et al. Lancet (2016). Our future: a Lancet commission on adolescent health and wellbeing 387(10036): 2423-2478. Doi: 10.1016/S0140-6736(16)00579-1.

4. UNICEF. Adolescent Demographics - UNICEF Data. 2016. Available at https://data.unicef.org/topic/adolescents/overview/: 2016;2016.

5. Engelman R, Rosen JE, Wong, Sylvia.The power of 1.8 billion. Adolescents, youth and the transformation of the future.unfpa. 2014 state of world population. 1.8 billion. 2014; Available from: https://www.unfpa.org/sites/default/files/pub-pdf/EN-SWOP14-Report_final-web.pdf

6. Report AC. World Population Monitoring. Adolescents and Youth, A Concise Report United Nations, New York, 2012

7. Nations U. Transforming our world: the 2030 agenda for sustainable development.2015. Available from: https://sustainabledevelopment.un.org/content/documents/21252030 Agenda for Sustainable Development web.pdf

8. The global Strategy For women's,Children's and Adolescents' Health Every women every child (20162030) 2016.

9. Sheehan P, Sweeny K, Rasmussen B, Wils A, Friedman HS, Mahon J, et al. Health Policy Building the foundations for sustainable development: a case for global investment in the capabilities of adolescents. Lancet. 2017;6736(17).

10. Darroch JE, Woog V, Bankole A, Ashford LS. ADDING IT UP: Costs and Benefits of Meeting the Contraceptive Needs of Adolescents. 2018;(May 2016).

11. Starrs AM, Ezeh AC, Barker G, Basu A, Bertrand JT, Blum R, et al. The Lancet Commissions Accelerate progress - sexual and reproductive health and rights for all: report of the Guttmacher - Lancet Commission. 2018;391.

12. Gibbs CM, Wendt A, Peters S, Hogue CJ. The Impact of Early Age at First Childbirth on Maternal and Infant Health. 2012;26:259-84.

13. Guttmacher institute. Adolescents' Need for and Use of Abortion Services in Developing Countries. 2016 https://www.guttmacher.org/fact-sheet/adolescents-need-and-use-abortion-servicesdeveloping-countries

14. WHO.2011. Guidelines for preventing early pregnancy and poor reproductive outcomes among adolescents in developing countries.

15. Ganchimeg T, Ota E, Morisaki N, Laopaiboon M, Lumbiganon P, Zhang J, Yamdamsuren B, Temmerman M, Say L, Tuncalp €O,Vogel JP, Souza JP, Mori R, on behalf of the WHO Multicountry 
Survey on Maternal Newborn Health Research Network. Pregnancy and childbirth, outcomes among adolescent mothers: a World Health Organization multicounty study. BJOG 2014; 121 (Suppl. 1): 4048.

16. The World Bank. 2007. World development report. Development and the Next Generation.

17. Elisabeth L. Åhman \& Iqbal H. Shah (2010) Contraceptive use, fertility, and unsafe abortion in developing countries, The European Journal of Contraception \& Reproductive Health Care, 15:sup2, S77-S82, DOI: 10.3109/13625187.2010.533004.

18. Biddlecom A, Riley T, Darroch JE, Sully E, Kantorová V. Future Scenarios of Adolescent Contraceptive Use, Cost and Impact in Developing Regions. 2018;(August).

19. John Cleland, Mohamed M Ali \& Iqbal Shah (2006) Trends in Protective Behaviour among Single vs. Married Young Women in Sub-Saharan Africa: The Big Picture, Reproductive Health Matters, 14:28, 17-22, DOI: 10.1016/S0968-8080(06)28250-8.

20. Sedekia Y, Jones C, Nathan R, Schellenberg J, Marchant T. Using contraceptives to delay first birth: a qualitative study of individual, community and health provider perceptions in southern Tanzania. 2017;1-13.

21. United Nations Population Fund (UNFPA) and ICPD25. Sexual and Reproductive Health and Rights: An essential element of Universal Health Coverage. Integrated definition of sexual and reproductive health and rights.

22. Fact sheet on teenage pregnancy in Ethiopia. https://www.rutgers.international/sites/rutgersorg/files/PDF/RHRNHLPF_A4leaflet_Ethiopia.pdf.

23. Federal democratic Republic of Ethiopia .Ministry of health . National Reproductive Health strategy (2016-2020), 2016.

24. Federal democratic Republic of Ethiopia .Ministry of health . National Reproductive health Strategy 2006 - 2015 ,(March 2006).

25. Federal democratic Republic of Ethiopia . Ministry of youth,sport and culture. Ethiopian national youth policy. March 2004.

26. Federal democratic Republic of Ethiopia .Ministry of health . National adolescent and Youth Health strategy (2016-2020), 2016.

27. Brittain et al. Youth-Friendly Family Planning Services for Young People: A Systematic Review Update. Am J Prev Med. 2018 November; 55(5): 725-735. doi: 10.1016/j.amepre.2018.06.010. surveys. Lancet Glob Health 2019; 7: e904-11 http://dx.doi.org/10.1016/.

28. Erica Sedlander, Jeffrey B. Bingenheimer, Mark C. Edberg, Rajiv N. Rimal, Hina Shaikh and Wolfgang Munar. Understanding modern contraception uptake in one Ethiopian community: a case study. Reproductive Health (2018) 15:111 https://doi.org/10.1186/s12978-018-0550-3

29. Ahmed S, Choi Y, Rimon JG, Alzouma S, Gichangi P, Guiella G, et al. Articles Trends in contraceptive prevalence rates in sub-Saharan Africa since the 2012 London Summit on Family Planning: results from repeated cross-sectional surveys. Lancet Glob Heal. 2019;7(7):e904-11. 
30. David J. Olson and Andrew Piller. Ethiopia's Emerging Family Planning Success. December 2013.

31. Susan Ontiri, Gathari Ndirangu, Mark Kabue, Regien Biesma, Jelle Stekelenburg and Collins Ouma. Long-Acting Reversible Contraception Uptake and Associated Factors among Women of Reproductive Age in Rural Kenya. 2019. Int. J. Environ. Res. Public Health 2019, 16, 1543; doi:10.3390/ijerph16091543

32. C.Emily Hendrick, Joshua N. Cone, Jessica Cirullo, Julie Maslowsky. Determinants of Long-Acting Reversible Contraception (LARC) Initial and Continued Use Among Adolescents in the United States. 2019 Adolescent Research Review https://doi.org/10.1007/s40894-019-00126-w

33. Dennis ML, Radovich E, Wong KLM, Owolabi O, Cavallaro FL, Mbizvo MT, et al. Pathways to increased coverage: An analysis of time trends in contraceptive need and use among adolescents and young women in Kenya, Rwanda, Tanzania, and Uganda. Reprod Health. 2017;14(1):1-13.

34. Tsui AO, Trevitt JL, Blanc AK, Gates M. Patterns and Trends in Adolescents ' Contraceptive Use and Discontinuation in Developing Countries and Comparisons. 2009;35(2):63-71.

35. By Eric E. Seiber, Jane T. Bertrand and Tara M. Sullivan. Changes in Contraceptive Method Mix In Developing Countries. International Family Planning Perspectives, 2007, 33(3):117-123

36. MacQuarrie, Kerry L.D., Lindsay Mallick, and Courtney Allen. 2017. Sexual and Reproductive Health in Early and Later Adolescence: DHS Data on Youth Age 10-19. DHS Comparative Reports No. 45. Rockville, Maryland, USA: ICF

37. Kafle, Ramesh Babu, Rasmita Paudel, Pragya Gartoulla, and Kerry L. D. MacQuarrie. 2019. Youth Health in Nepal: Levels, Trends, and Determinants. DHS Further Analysis Reports No. 116. Rockville, Maryland, USA: ICF

38. Santelli JS, Lindberg LD, Finer LB, Singh S. Explaining Recent Declines in Adolescent Pregnancy in the United States: The Contribution of Abstinence and Improved Contraceptive Use. 2007;97(1):1506.

39. Potter J, Trussell J, Moreau C. Trends and determinants of reproductive health service use among young women in the USA t. 2009;24(12):3010-8

40. Singh A, Singh KK, Verma P. Knowledge, attitude and practice GAP in family planning usage: an analysis of selected cities of Uttar Pradesh. Contracept Reprod Med [Internet]. 2016;1(1):1-10. Available from: http://dx.doi.org/10.1186/s40834-016-0031-4

41. Hounton S, Barros AJD, Amouzou A, Shiferaw S, Maı A, Akinyemi A. Patterns and trends of contraceptive use among sexually active adolescents in Burkina Faso, Ethiopia, and Nigeria: evidence from cross-sectional studies. 2015;1(October):1-11.

42. Nyarko SH. Prevalence and correlates of contraceptive use among female adolescents in Ghana. 2015;4-9.

43. Hossain ME, Hoq MN. Determinants of Contraception Use among Female Adolescents in Bangladesh Determinants of Contraception Use among Female Adolescents in Bangladesh. 2012;(September).

44. Fekadu GA, Omigbodun AO, Roberts OA, Yalew AW. Factors associated with long acting and permanent contraceptive methods use in Ethiopia. 2019;3:1-11 
45. Nakirijja DS. iMedPub Journals Socio-economic Determinants of Access to and Utilization of Contraception among Rural Women in Uganda: The Case of Wakiso District Background of the Research. 2018;1-20.

46. Chima V, Alawode OA, Peter S, Kibira S. contraceptive use among female adolescents in rural Nigeria: Does exposure to family planning messages matter? A cross-sectional study [ version 2; peer review: 1 approved ] Gates Open Research This article is included in the International. 2019;113

47. Mohamad I. Brooks1, Nicole E. Johns, Anne K. Quin, Sabrina C. Boyce, Ibrahima A. Fatouma, Alhassane O. Oumarou, Aliou Sani and Jay G. Silverman. Can community health workers increase modern contraceptive use among young married women? A cross-sectional study in rural Niger. Reproductive Health (2019) 16:38. https://doi.org/10.1186/s12978-019-0701-1

48. Johannes Bitzer, Virginia Abalos, Dan Apter, Ricardo Martin, Amanda Black \& on behalf of the Global CARE (Contraception: Access, Resources, Education) Group (2016) Targeting factors for change: contraceptive counselling and care of female adolescents, The.

49. Pradesh U, Dehingia N, Dixit A, Averbach S, Choudhry V, Dey A, et al. Family planning counseling and its associations with modern contraceptive use, initiation, and continuation in rural. 2019;1-11.

50. WHO, Sixty-Fifth World Health Assembly. Early marriages, adolescent and young pregnancies, Report by the Secretariat. 16 March 2012.

51. Montazeri S, Gharacheh M, Mohammadi N, Rad JA, Ardabili HE. Determinants of Early Marriage from Married Girls ' Perspectives in Iranian Setting: A Qualitative Study. 2016;2016.

52. Nicola J. e tal. September 2014. Early marriage and education: the complex role of social norms in shaping Ethiopian adolescent girls'lives. Country Report.

53. Raj A, Salazar M, Jackson EC, Wyss N, Mcclendon KA, Khanna A. Students and brides: a qualitative analysis of the relationship between girls ' education and early marriage in Ethiopia and India. 2019;1-20.

54. Erulkar A. Adolescence lost: The realities of child marriage. J Adolesc Heal [Internet]. 2013;52(5):513-4. Available from: http://dx.doi.org/10.1016/j.jadohealth.2013.03.004

\section{Tables}

Table 1 : Distribution of sexually active female adolescents age $15-19$ by their background characteristics, Ethiopia DHS 2016 


\begin{tabular}{|c|c|c|c|}
\hline \multicolumn{2}{|l|}{ Variable } & \multirow{2}{*}{$\begin{array}{l}\text { Frequency } \\
161\end{array}$} & \multirow{2}{*}{$\begin{array}{l}\text { Percent } \\
32.0\end{array}$} \\
\hline Age category & $15-17$ & & \\
\hline \multicolumn{2}{|c|}{$18-19$} & 343 & 68.0 \\
\hline \multirow[t]{3}{*}{ Education of respondent } & No education & 143 & 28.4 \\
\hline & Primary & 305 & 60.6 \\
\hline & Secondary and above & 56 & 11.0 \\
\hline \multirow[t]{2}{*}{ Place of residence } & Urban & 64 & 12.7 \\
\hline & Rural & 440 & 87.3 \\
\hline \multirow[t]{3}{*}{ Marital status } & Married & 458 & 91.0 \\
\hline & Never married & 23 & 4.5 \\
\hline & Divorced/separated & 23 & 4.5 \\
\hline \multirow[t]{3}{*}{ Wealth index } & Poor & 230 & 45.6 \\
\hline & Average & 97 & 19.3 \\
\hline & Rich & 177 & 35.1 \\
\hline \multirow[t]{4}{*}{ Religion } & Muslim & 211 & 41.9 \\
\hline & Orthodox Christian & 201 & 39.9 \\
\hline & Other Christian & 90 & 17.9 \\
\hline & Other & 2 & 0.3 \\
\hline \multirow[t]{9}{*}{ Ethnicity } & Oromo & 199 & 39.5 \\
\hline & Amhara & 155 & 30.7 \\
\hline & Tigraie & 34 & 6.8 \\
\hline & Sidama & 22 & 4.4 \\
\hline & Somalie & 17 & 3.3 \\
\hline & Walaita & 12 & 2.4 \\
\hline & Gamo & 10 & 1.9 \\
\hline & Guragie & 8 & 1.5 \\
\hline & Other & 48 & 9.4 \\
\hline \multirow[t]{2}{*}{ Respondent occupation } & Not working & 300 & 59.6 \\
\hline & Agriculture & 102 & 20.3 \\
\hline
\end{tabular}




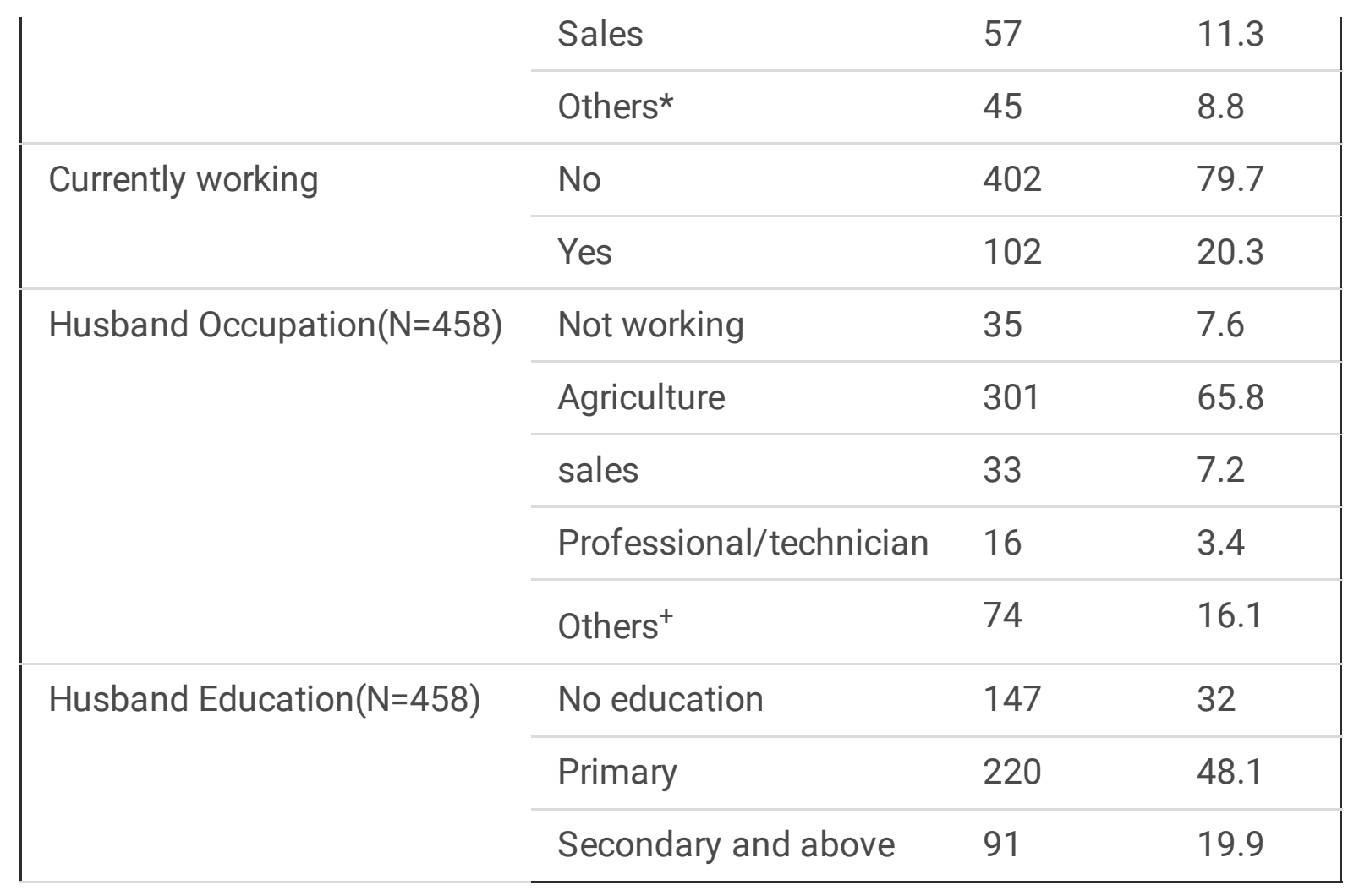

*professional/managerial/technical, services, skilled and unskilled manual

${ }^{+}$skilled and unskilled manual, services, I don't know

Table 2: Distribution of adolescents age 15-19 by their exposure to family planning information, knowledge about fertility and contraceptive method, Ethiopia DHS 2016 


\begin{tabular}{|c|c|c|c|}
\hline Variables & & Frequency & Percent \\
\hline \multirow{2}{*}{$\begin{array}{l}\text { Heard family planning message on radio on last few } \\
\text { months }\end{array}$} & Yes & 91 & 18.1 \\
\hline & No & 413 & 81.9 \\
\hline \multirow{2}{*}{$\begin{array}{l}\text { Watch family planning messages on TV on last few } \\
\text { months }\end{array}$} & Yes & 68 & 13.4 \\
\hline & No & 436 & 86.6 \\
\hline \multirow{2}{*}{$\begin{array}{l}\text { Read about family planning messages on } \\
\text { newspaper/magazine last few months }\end{array}$} & Yes & 21 & 4.2 \\
\hline & No & 483 & 95.8 \\
\hline \multirow{2}{*}{$\begin{array}{l}\text { Received family planning text message on mobile } \\
\text { phone }\end{array}$} & Yes & 5 & 1.1 \\
\hline & No & 498 & 98.9 \\
\hline \multirow{2}{*}{$\begin{array}{l}\text { Visited by field worker in the last } 12 \\
\text { months }\end{array}$} & Yes & 101 & 20.1 \\
\hline & No & 402 & 79.9 \\
\hline \multirow{2}{*}{$\begin{array}{l}\text { Field worker talk about family } \\
\text { planning }\end{array}$} & Yes & 50 & 9.9 \\
\hline & No & 51 & 10.2 \\
\hline \multirow{2}{*}{$\begin{array}{l}\text { Visited health facility in the last } 12 \\
\text { months }\end{array}$} & Yes & 211 & 42.0 \\
\hline & No & 292 & 58.0 \\
\hline \multirow{2}{*}{$\begin{array}{l}\text { Told about family planning in the health } \\
\text { facility }\end{array}$} & Yes & 77 & 15.3 \\
\hline & No & 135 & 26.7 \\
\hline \multirow[t]{6}{*}{ Knowledge of ovulatory period } & $\begin{array}{l}\text { During her } \\
\text { period }\end{array}$ & 37 & 7.3 \\
\hline & $\begin{array}{l}\text { After period } \\
\text { ended }\end{array}$ & 148 & 29.4 \\
\hline & $\begin{array}{l}\text { Middle of the } \\
\text { cycle }\end{array}$ & 76 & 15.0 \\
\hline & $\begin{array}{l}\text { Before period } \\
\text { begins }\end{array}$ & 33 & 6.5 \\
\hline & At any time & 116 & 23.0 \\
\hline & Do not know & 95 & 18.8 \\
\hline \multirow[t]{3}{*}{ Knowledge about any contraceptive method } & $\begin{array}{l}\text { Knows no } \\
\text { method }\end{array}$ & 7 & 1.3 \\
\hline & $\begin{array}{l}\text { Knows only } \\
\text { traditional } \\
\text { method }\end{array}$ & 4 & 0.7 \\
\hline & Knows modern & 494 & 98.0 \\
\hline
\end{tabular}




\begin{tabular}{|llll|}
\hline Number of living children & \multicolumn{3}{l|}{ method } \\
& No child & 308 & 61.1 \\
\cline { 2 - 3 } & One child & 173 & 34.4 \\
\hline Decision maker on contraceptive use & Two and more & 22 & 4.5 \\
\hline $\begin{array}{l}\text { Mainly } \\
\text { Respondent }\end{array}$ & 34 & 19.7 \\
\hline Mainly husband & 3 & 1.9 \\
\hline Joint decision & 133 & 78.4 \\
\hline
\end{tabular}

Table 3: Bivariate and multivariate logistic regression model showing predictors of contraceptive use among sexually active adolescents, 2016 EDHS 


\begin{tabular}{|c|c|c|c|}
\hline Variables and its category & & COR $[95 \% \mathrm{Cl}]$ & AOR $[95 \% \mathrm{Cl}]$ \\
\hline \multirow[t]{2}{*}{ Adolescent age category } & $15-17$ & $.408 \quad(.270$ & $\begin{array}{l}.524 \\
1.260)\end{array}(.218$ \\
\hline & $18-19$ & 1 & 1 \\
\hline \multirow[t]{2}{*}{ Place of residence } & Urban & $\begin{array}{l}3.256(1.882 \\
5.632)\end{array}$ & $\begin{array}{l}0.692(.113 \\
4.238)\end{array}$ \\
\hline & Rural & 1 & 1 \\
\hline \multirow[t]{2}{*}{$\begin{array}{l}\text { Heard family planning on radio } \\
\text { last few months }\end{array}$} & Yes & $\begin{array}{l}2.365(1.491 \\
3.750)\end{array}$ & $\begin{array}{l}1.046 \\
2.699)\end{array}(.405$ \\
\hline & No & 1 & 1 \\
\hline \multirow[t]{2}{*}{$\begin{array}{l}\text { Heard family planning on TV last } \\
\text { few months }\end{array}$} & Yes & $\begin{array}{l}3.323(1.943 \\
5.682)\end{array}$ & $\begin{array}{l}0.374 \\
1.506)\end{array}(.093$ \\
\hline & No & 1 & 1 \\
\hline \multirow[t]{2}{*}{ Told about FP at health facility } & Yes & $\begin{array}{l}3.083(1.721 \\
5.523)\end{array}$ & $\begin{array}{l}3.115(1.385 \\
7.007) *\end{array}$ \\
\hline & No & 1 & 1 \\
\hline \multirow[t]{3}{*}{ Husband Education } & No education & $.422 \quad(.247$ & $\begin{array}{l}1.083 \\
3.671)\end{array}(.320$ \\
\hline & Primary & $\begin{array}{l}.445 \quad(.271 \\
.731)\end{array}$ & $\left.\begin{array}{l}0.330 \\
1.015)\end{array}\right)(.107$ \\
\hline & Secondary \& above & 1 & 1 \\
\hline \multirow[t]{3}{*}{ Wealth Index } & Poor & 1 & 1 \\
\hline & Average & $\begin{array}{l}1.886(1.135 \\
3.134)\end{array}$ & $\begin{array}{l}0.424 \\
1.380)\end{array}(.130$ \\
\hline & Rich & $\begin{array}{l}\text { 4.701(3.070, } \\
7.198)\end{array}$ & $\begin{array}{l}3.662 \\
9.913) *\end{array}$ \\
\hline \multirow[t]{4}{*}{ Respondent occupation } & Not working & 1 & 1 \\
\hline & Agriculture & $\begin{array}{l}1.407 \\
2.222)\end{array}(.891$ & $\begin{array}{l}1.841 \\
5.359)\end{array}(.632$ \\
\hline & Sales & $\begin{array}{l}2.730 \\
5.154)\end{array}(1.447$ & $\begin{array}{l}2.599 \\
17.455)\end{array}$ \\
\hline & $\begin{array}{l}\text { Others (skilled, unskilled } \\
\text { manual) }\end{array}$ & $\left.\begin{array}{l}1.048 \\
1.902)\end{array}\right)(.577$ & $\begin{array}{l}0.468 \\
2.587)\end{array}(.085$ \\
\hline \multirow[t]{2}{*}{ Respondent education } & No education & $\begin{array}{l}.206 \\
.399)\end{array}$ & $\begin{array}{c}0.044 \\
.231)^{*}\end{array} \quad(.008$ \\
\hline & Primary & $(.203$ & $0.101 \quad(.024$ \\
\hline
\end{tabular}


Secondary \& above

Yes

Currently working
No

1

$1.797(1.160$

2.784) 1

1

$2.622(.660$ 10.412)

* Significant value at 0.05

\section{Figures}

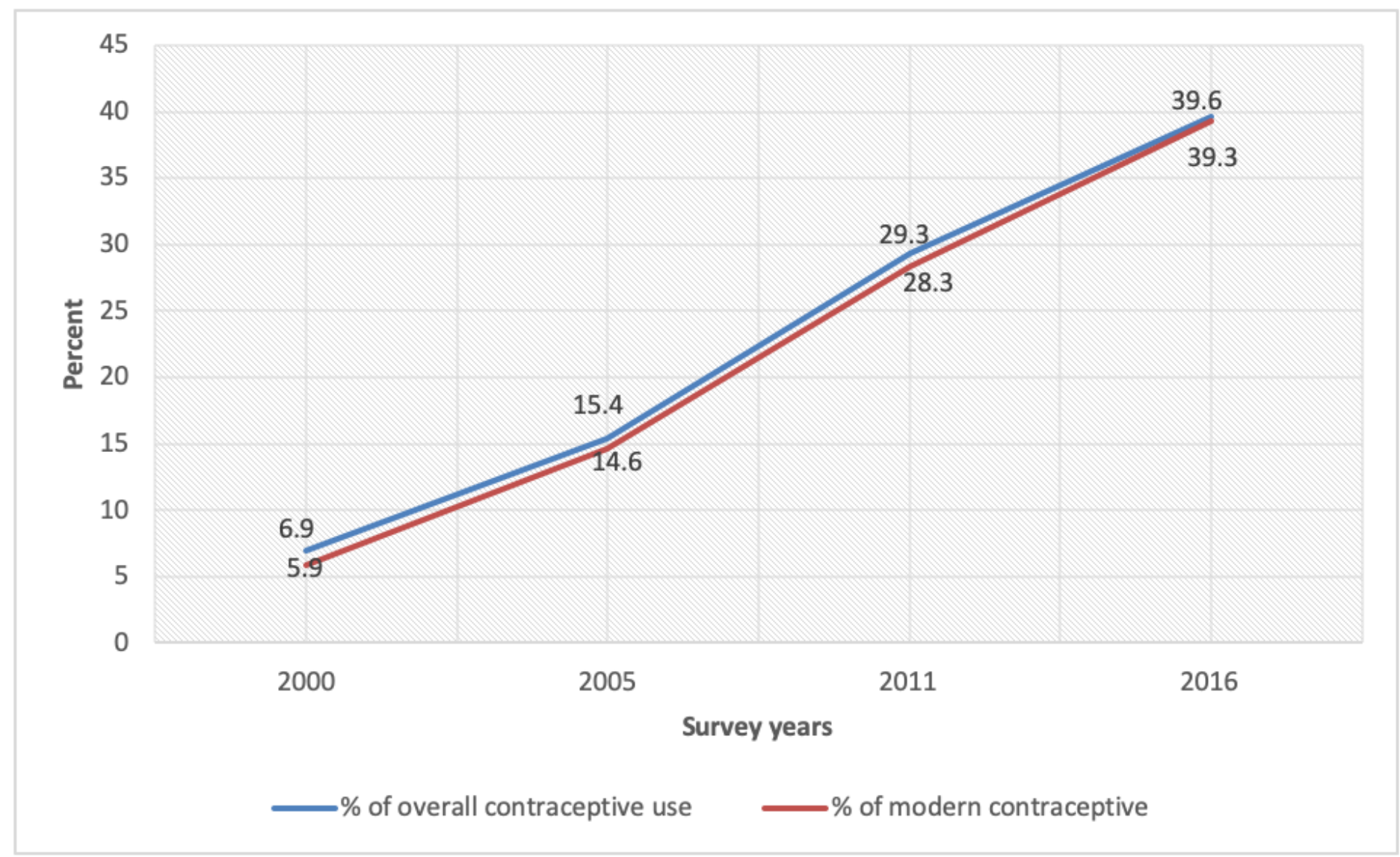

\section{Figure 1}

Trends in use of modern contraceptives among sexually active adolescent, Ethiopia DHS 2000-2016 


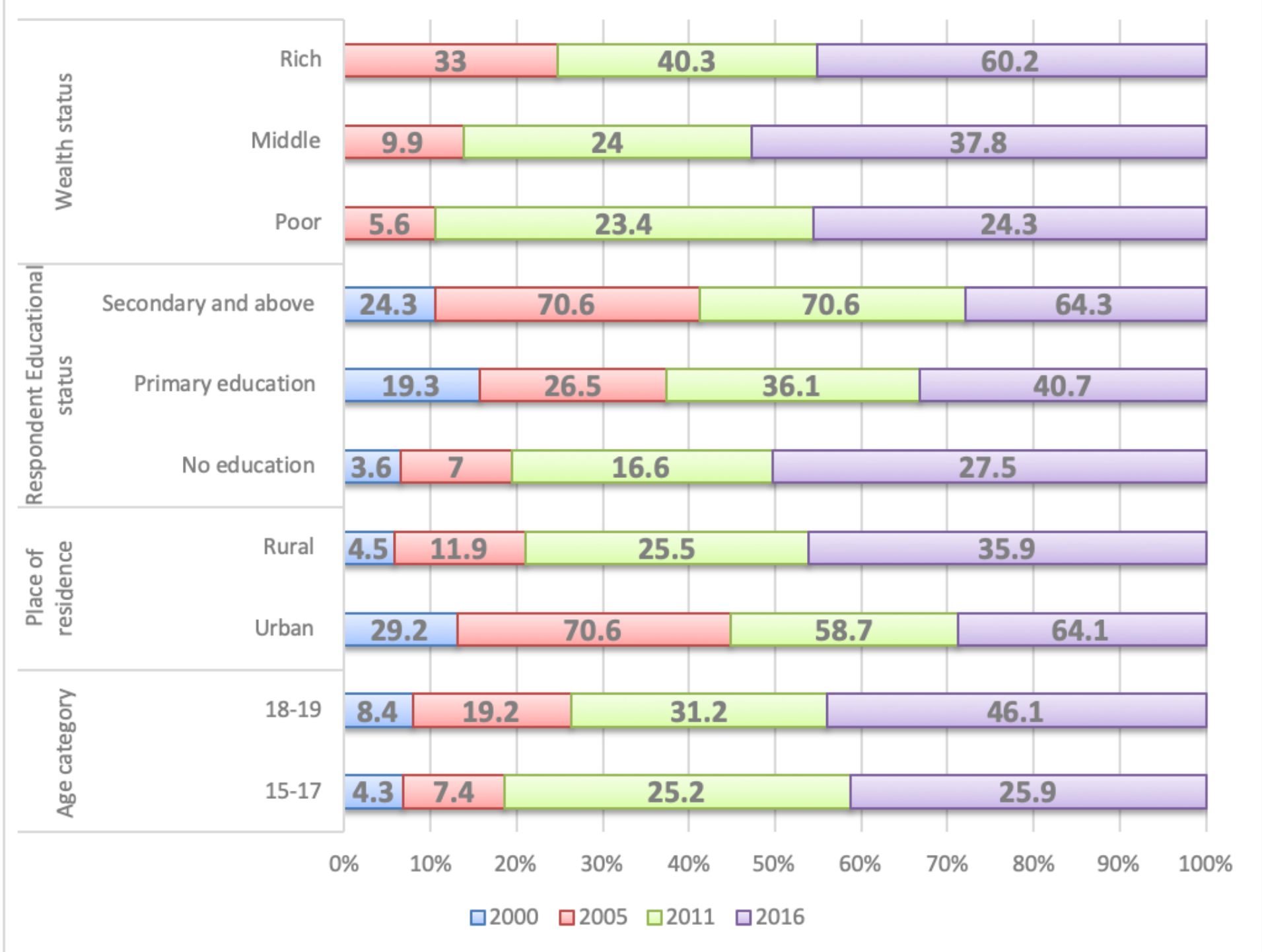

\section{Figure 2}

Differentials in contraceptive use among sexually active adolescent by background characteristics, Ethiopia DHS 2000-2016 


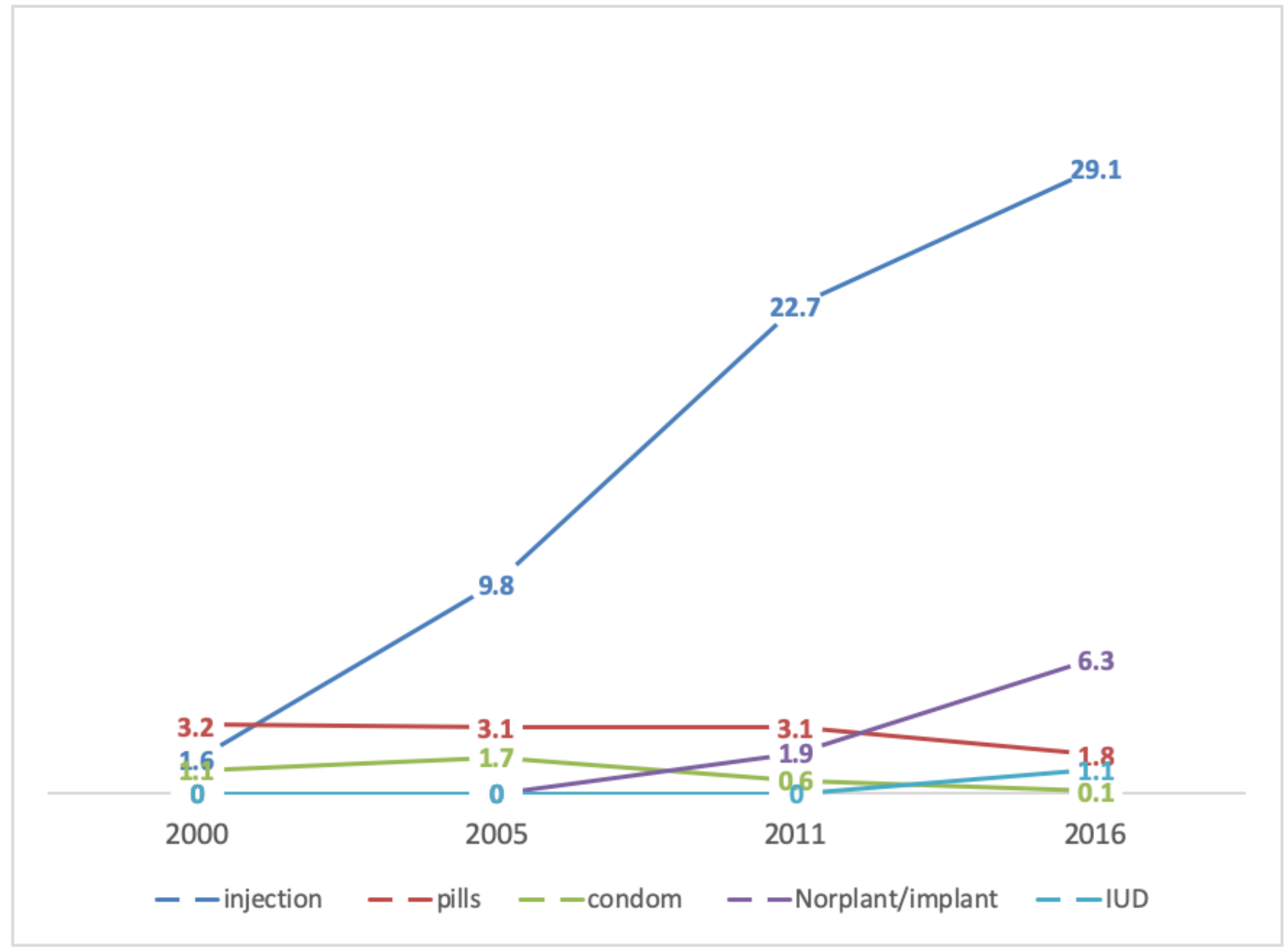

\section{Figure 3}

Trends in method mix contraceptive use among sexually active adolescent, Ethiopia DHS 2000-2016

\section{Supplementary Files}

This is a list of supplementary files associated with this preprint. Click to download.

- supplementaryfile.docx 